\title{
Ten years after the FDA black box warning for antidepressant drugs: a critical narrative review
}

\author{
Juan Carlos Martínez-Aguayo1, Marcelo Arancibia2,3, Sebastián Concha4, Eva Madrid5,6 \\ 1 Department of Pediatrics, School of Medicine, Faculty of Medicine, Universidad de Valparaíso, Valparaíso, Chile. \\ 2 Department of Psychiatry, Faculty of Medicine, Universidad de Valparaíso, Valparaíso, Chile. \\ ${ }^{3}$ Department of Medical Humanities and Family Medicine, Universidad de Valparaíso, Valparaíso, Chile. \\ ${ }_{4}$ School of Medicine, Faculty of Medicine, Universidad de Valparaíso, Valparaíso, Chile. \\ 5 Department of Public Health, School of Medicine, Faculty of Medicine, Universidad de Valparaíso, Valparaíso, Chile. \\ ${ }^{6}$ Biomedical Research Centre, School of Medicine, Faculty of Medicine, Universidad de Valparaíso, Valparaíso, Chile.
}

Received: 5/27/2016 - Accepted: 6/30/2016

DOl: 10.1590/0101-60830000000086

\begin{abstract}
Background: The United States Food and Drug Administration (FDA) has warned about the increased suicidality risk associated with the use of selective serotonin reuptake inhibitors (SSRI) and venlafaxine in children and adolescents. Objectives: To critically appraise the available evidence supporting the FDA Black box warning concerning to the use of antidepressants in child and adolescents. Methods: A critical review of articles in Medline/PubMed and SciELO databases regarding the FDA Black box warning for antidepressants, and the impact of FDA warnings on antidepressant prescriptions and suicide rates. Results: The warning was based on surveys that did not report either cases of suicide nor a significant difference supporting an increased suicidality rate. The concept was defined in an ambiguous way and there is currently more available evidence to support such definition. The use of SSRI and venlafaxine has been associated to lower suicidality rates, but the prescription fall due to the warning increased suicide rates. Discussion: Suicidality is an inherent feature of depressive disorders so it would be desirable to consider how much of the phenomenon may be attributed to antidepressants per se. It would be appropriate to consider that suicide rates might increase also as a consequence of the warning.
\end{abstract}

Martínez-Aguayo JC et al. / Arch Clin Psychiatry. 2016;43(3):60-6

Keywords: Antidepressants, serotonin uptake inhibitors, suicide, United States Food and Drug Administration.

\section{Introduction}

Approximately 2 to $3 \%$ of children and 6 to $8 \%$ of teenagers suffer from major depressive disorder, considered the main determinant of suicide, and a leading cause of death among teenagers ${ }^{1}$. In fact, depression is present among 46 to $64 \%$ of suicidal adolescents ${ }^{2-4}$; an increase of over twenty times the risk of completed suicide ${ }^{5}$. Thus, suicidal conduct is included in the fifth edition of the Diagnostic and Statistical Manual of Mental Disorders as a diagnostic criterion to the affective disorders 6 .

While a positive correlation exists between the risk of suicide and the severity of affective disorders, subsequent treatment plays a role as a preventive measure. The introduction of new antidepressants (AD), particularly selective serotonin reuptake inhibitors (SSRI) have been a useful mechanism in the rehabilitation of depression, with some countries observing a decrease in suicide rates ${ }^{7}$.

Until the 1980s, depression was primarily treated with AD such as monoamine oxidase inhibitors and tricyclics. Since overdoses of these drugs are potentially lethal, in some cases they were even used as a way to carry out suicidal acts, a situation still worrisome among prescribers, and which opened a discussion surrounding suicidality ${ }^{8-10}$. Nevertheless, the notion that $\mathrm{AD}$ precipitate suicide in depressed people was noted by Kielholz and Battegay as early as 1958, relating it to "the rollback phenomenon", which describes the risk associated with these medications in mobilizing severely depressed patients to attempt suicide as a consequence of psychomotor improvement during the first period of therapy, while still affectively impaired ${ }^{11}$.

The SSRI do not escape from inclusion in the discussion of suicide, on the grounds that Teicher et al. reported six cases of patients with suicidal ideas being treated with fluoxetine, highlighting that none had presented such phenomenon previously ${ }^{12}$. That report induced the United States Food and Drug Administration (FDA) to create a panel of experts that gave neither recommendations nor warnings regarding the drug. This despite blind randomized trials which repudiated a link between previously mentioned $\mathrm{AD}$ and increased suicidality ${ }^{13}$. Subsequently, in 2004, the FDA created a new advisory committee that led to one of the most contentious debates linked to suicide: the association between SSRI consumption and the inducement of suicide in children and adolescents ${ }^{14}$. The current FDA warning alludes to an increase in suicidality, a vague concept ranging from mere ideation to the completion of suicide ${ }^{10-11}$, despite the lack of epidemiologic evidence showing a relationship between suicide rates and the prescription of new AD medications ${ }^{15}$.

This intent of this review is to provide a critical viewpoint concerning the FDA warning, its supporting evidence in terms of therapeutic (AD prescription) and epidemiological outcome (suicide rates), the studies that support it, and the research that reinforces the usage of $\mathrm{AD}$.

\section{Methods}

An exhaustive bibliographic search was done through the available articles on the database PubMed, Cochrane Central, SciELO, and on specialized consulting texts, using key words as "suicide", "adolescence", "antidepressants" and "FDA". The date range of the search was from January 1988 through June 2014.

\section{Results}

\section{Black box warning issued by the FDA}

In 2003, the United Kingdom's Department of Health and the FDA issued a public warning against the use of paroxetine in people younger than 18 years old. In August of the same year, Wyeth Laboratories, manufacturer of venlafaxine (dual AD), suggested that physicians should cease prescribing the aforementioned drug in children and adolescents, due to low efficacy and the risk of increasing hostile feelings and suicidal tendencies. Yet in October, 
the FDA issued research results involving citalopram, fluoxetine, fluvoxamine, nefazodone, sertraline and venlafaxine, recommending physicians to be cautious in prescribing an $\mathrm{AD}$, with insufficient data supporting the thesis of suicide increase ${ }^{16}$. In December, the British Medicines and Healthcare Products Regulatory Agency suggested that physicians cease prescribing $\mathrm{AD}$ for people younger than eighteen (excluding fluoxetine), based on three investigations that cited an apparent increase in suicidal tendencies among children and adolescents ${ }^{17}$. However, the only one of these investigations that were published examined paroxetine versus placebo in the treatment of major depressive disorder, and reported a 3\% increase of suicidality for the $\mathrm{AD}$ (fourteen out of 378 patients) versus $2.5 \%$ for the placebo (seven out of 285 patients), indicating no statistically significant difference ${ }^{18}$. Additionally, the definition of suicidality or suicidal tendencies used was confusing, and included self-harm, suicidal planning and ideation, attempt or completed suicide. Neither of reports stated any death from suicide ${ }^{18,19}$.

The FDA alert, called the Black Box warning, was based on short-term investigations (between four and sixteen weeks) that showed a higher risk of suicidal tendencies ( $4 \%$ on average), the double researched for a placebo, without any accomplished suicides reported ${ }^{20}$. Such action provoked a marked decrease in $\mathrm{AD}$ prescription $^{21}$. The American Medical Association and the American Psychiatric Association subsequently warned of the potentially negative consequences that a decline in $\mathrm{AD}$ access could have on patients, who might otherwise be significantly benefited by their prescription ${ }^{22}$.

Finally, in October 2004, after assessing a total of 24 studies, the FDA extended the Black Box warning to encompass all AD prescribed to people younger than eighteen. Many of these investigations have not been unveiled to the scientific community, so their methodological rigour could be arguable ${ }^{23}$. In February 2005, the warning was modified by the FDA, stating in a more precise way that the usage of $\mathrm{AD}$ would produce an increase in suicidal tendencies and ideations, but not in accomplished suicides ${ }^{24}$. In Table $1^{19}$ suicidal risks for some $\mathrm{AD}$ are described, whereas Table 2 shows the results obtained by the FDA when re-analyzing the related events with suicidal acts in young people under $\mathrm{AD}$ treatment. For general pathologies the relative risk of suicidal events ascended up to 1.95 , without witnessing a statistical superiority with placebo in any case ${ }^{23}$.

Table 1. Suicidality rate according to antidepressant versus placebo

\begin{tabular}{|l|c|c|c|c|}
\hline Drug & N & $\begin{array}{c}\text { Suicidalitya } \\
\text { Antidepressant } \\
(\%)\end{array}$ & $\begin{array}{c}\text { Suicidalitya } \\
\text { Placebo (\%) }\end{array}$ & P value \\
\hline Fluoxetine & 458 & 3.6 & 3.8 & 0.9 \\
\hline Sertraline & 373 & 2.7 & 1.1 & 0.45 \\
\hline Citalopram & 418 & 8.9 & 7.3 & 0.4 \\
\hline Paroxetine & 663 & 3.7 & 2.5 & 0.5 \\
\hline Venlafaxine & 334 & 2 & 0 & 0.25 \\
\hline
\end{tabular}

a Ideation, suicide attempt or self-harm. Modified from Brent y Birhamer19.

Table 2. Relative risk for suicidal behaviors on clinical trials according to antidepressant

\begin{tabular}{|l|c|c|}
\hline Antidepressant & Major depression studies & All pathologies studies \\
\hline Citalopram & 1.37 & 1.37 \\
\hline Fluvoxamine & No research & 5.52 \\
\hline Paroxetine & 2.15 & 2.65 \\
\hline Fluoxetine & 1.53 & 1.52 \\
\hline Sertraline & 2.16 & 1.48 \\
\hline Venlafaxine XR & 8.84 & 4.97 \\
\hline Mirtazapine & 1.58 & 1.58 \\
\hline Nefazodone & No events & No events \\
\hline Bupropion & No research & No events \\
\hline Total & 1.66 & 1.95 \\
\hline
\end{tabular}

Modified Cheung et al.23.
In a systematic FDA review, 24 studies were included, of nine SSRI and other AD families, with a total of 4,582 patients with anxiety and affective disorders. Their results showed a relative risk of suicidal behavior and ideation, and self-aggressive behaviors associated with the usage of SSRI in major depressive disorder above 1.66 (CI 95\%, $1.02-2.68$ ), whereas the relative risk in the total of $\mathrm{AD}$ examined for all evaluated pathologies was 0.002 (CI 95\%, $0.01-0.03)$. At the same time, the Treatment for Adolescents with Depression Study, a multicenter randomized trial testing the efficacy of $\mathrm{AD}$, reported a statistically significant higher relative risk for SSRI 25 . Also, a systematic review conducted by Hetrick et al, which looked at nineteen trials of a range of newer $\mathrm{AD}$ compared with placebo, with a total of 3,335 participants showed that those treated with AD had lower depression severity scores and higher rates of response/ remission than those on placebo. However, there was evidence of an increased risk (58\%) of suicide-related outcomes for those on AD. Nevertheless, the study's trials excluded young people at high risk of suicide and many co-morbid conditions, so participants were likely to be less unwell than those seen in clinical practice. Participants had limited information about the risk of bias, high dropout rates and issues regarding measurement instruments and the clinical usefulness of outcomes, which were often defined differently across trials. The authors concluded that: 1) Due to the methodological limitations of the included trials in terms of internal and external validity, the results must be interpreted with caution; 2) The size and clinical meaningfulness of statistically significant results are uncertain; 3) Fluoxetine might be the medication of choice if a decision to use medication is agreed given the guideline recommendations ${ }^{26}$. On the other hand, an independent meta-analysis, that included 39 studies of $\mathrm{AD}$, did not reveal any significant difference in the ideation or risk of attempted suicide, where one in 147 patients would demonstrate an increased risk ${ }^{27}$. Dubicka et al. pointed out similar findings about pediatric depression, examining the suicidal and self-aggressive conduct rates. Total frequency for these events was $4.8 \%$ with an $\mathrm{AD}$ and $3 \%$ with a placebo. When using heterogeneity-sensitive random effects analysis, the relative risk did not encounter statistical significance $(\mathrm{RR}=1.58 ; \mathrm{p}=0.083)^{28}$.

In May 2012, the American Academy of Child and Adolescent Psychiatry made a public announcement stating that SSRI and other $\mathrm{AD}$ would be useful in the treatment of depression ${ }^{29}$, suggesting that therapies with $\mathrm{AD}$ continue, but include informing and explaining to the patient's family the existing warning. Moreover, it was advised not to apply such warnings to all children prescribed $\mathrm{AD}$ for depression based on: 1) evidence that all $\mathrm{AD}$ are efficient in major depression (mainly supported for studies in people above eighteen years old); 2) The study reporting exacerbation of suicidal events does not have sufficient statistical power. Most psychiatrists think that if, in some cases that statement might be true, it is preferable to monitor them rather than to suppress therapy; 3 ) According to the FDA, only $2 \%$ to $3 \%$ of children and adolescents increased their suicidal ideations or self-aggressive behaviors after using $\mathrm{AD}$, having no reports of actual suicide; 4) The cost of patients' depression is higher than an increase of $2 \%$ in suicidality; 5) At the onset of ideation or suicidal behavior in the beginning of $\mathrm{AD}$ treatment, or after a dose adjustment, close surveillance of the patient is recommended during the first month. This is to provide a list of alarm symptoms to be alert to, such as the appearance of or increase in symptoms such as anxiety, panic attacks, psychomotor agitation, akathisia, insomnia, irritability, hostility or aggressiveness, impulsivity, hypomania, and mania. Despite the aforementioned facts, there is no causal link between these symptoms and ideation or suicidal behavior; 6) If the symptoms were severe, had an abrupt start or were not initially present, a change in the therapeutic plan should be considered 30,31

Finally, in 2014 the results of a retrospective investigation were published that considered 36,842 children from ages six to eighteen who used fluoxetine, sertraline, paroxetine, citalopram, escitalopram, and venlafaxine, all of which were included in the FDA warning (fluoxetine is the only allowed $\mathrm{AD}$ to be prescribed in children and 
adolescents by FDA). The research stated that the rates of attempted suicide did not differ significantly among people who received fluoxetine and the other AD not recommended by the FDA ${ }^{32}$.

\section{Evidence that supports the usage of antidepressants}

The individual risk of suicide is multifactorial, but depression stands out as an important factor. Considering that the methodological quality of the research on $\mathrm{AD}$ therapy has improved since the warning issued by the FDA, the aspects that support the usage of $\mathrm{AD}$ will be described ${ }^{33}$.

\section{Usage of antidepressants and decrease in suicidal rates}

Despite the FDA warnings, there is much AD treatment that results in reducing suicide risks. Thus, in the "Antidepressant Age" (19601992) suicide rates associated with affective disorders were reduced from 6.3 per thousand at the beginning of the Twentieth Century to 3.3 per thousand 34,35 . In a study, Kuba et al. found that suicidal ideation, self-mutilation and suicide attempts decreased from $47.1 \%$ to $22.9 \%$ after three months of AD therapy in patients with a mean age of 15.4 years $^{36}$.

The Centers for Disease Control and Prevention indicate that the suicide rate of teenagers increased throughout the 1970's and 1980 's ${ }^{14}$, followed by its decrease of $20 \%$ to $30 \%{ }^{37}$ associated with the introduction of SSRI in $1988^{38-41}$. In fact, between 1985 and 1999, the suicide rate in the US decreased from 12.4 to 10.7 per 100,000 , while the prescription of AD (predominantly SSRI) was quadrupled $^{42}$. In North American teenagers, for every $1 \%$ increase in $\mathrm{AD}$ prescription, there was a decrease of 0.23 suicides per 100,000 annually $(\mathrm{p}<0.001)^{43,44}$. Additionally, the $13 \%$ increase in SSRI sales in 27 countries during 1999 reduced suicide rates by $2.5 \%$ in those countries. Particularly in Sweden, suicide fell by $25 \%$, which was likely associated with the $400 \%$ increase in $\mathrm{AD}$ sales there ${ }^{45}$. Likewise, Bramness et al., through observations made in Norway between 1980 and 2004, found a significant relationship between the rise of non-tricyclic AD sales and the decreased suicide rates ${ }^{46}$. On the other hand, SSRI were introduced in Japan in 1999, increasing its $\mathrm{AD}$ prescription by $54 \%$. According to the Japanese Ministry of Health, suicide rates after that year decreased by $6 \%{ }^{47}$.

\section{Elapsed time in antidepressant treatment}

Simon et al. established a temporal correlation between the usage of $\mathrm{AD}$ and suicide rates, reporting that the instances of suicide were significantly lower than the month prior to the beginning of $\mathrm{AD}$ treatment. In a total of 65,103 users of $\mathrm{AD}$, the suicide risk during the acute phase of the treatment was one per 3,000, while the suicide attempt was one per 1,000, without a significant association between an increase in these risks and SSRI therapy. Meanwhile, the suicide risk of children and teenagers during the six months following antidepressant indication was 314 per 100,000, this being higher than the month previous to the prescription, showing a decrease immediately after onset of medication and a decline during its usage. While the estimated risk remained relatively stable over the next six months, their confidence intervals were wide, validating the lack to the number of observed events. Researchers assert that a significant increase of suicide risks or serious suicidal attempts existed after initiating SSRI therapy ${ }^{48}$. These findings were confirmed by Simon \& Savarino, thus proving the reduction in the suicide rate after $\mathrm{AD}$ treatment ${ }^{49}$. Similarly, Jick et al. found a strong relationship between suicidal behavior and the time elapsed since the beginning of the $\mathrm{AD}$ therapy. Compared to a group that had accomplished ninety or more days of treatment, those who had between one and nine days were four times more likely to commit a non-fatal suicidal act, while those that completed between ten and twenty-nine days were three 3 times more likely, and those who completed reached between 30 and 89 days of treatment only 1.5 times more likely. Moreover, those who had between one and nine days of treatment were 38 times more likely to commit suicide, those treated between ten and twenty-nine days, were 5.1 times more likely, and finally, those that completed between 30 and 89 days, twice as likely ${ }^{50}$.

\section{Usage of particular drugs in high risk cases}

Mines et al. compared a series of clinical parameters and morbidity records in patients assigned to fluoxetine, citalopram and venlafaxine. The venlafaxine patients group was considered to be the most severe due to their psychopathological history with increased suicide risk. Confirming that statement, those treated with fluoxetine and citalopram showed 2.75 times and 2.43 times less suicidal behavior respectively, compared to those who received venlafaxine ${ }^{51}$.

Venlafaxine has been one of the most criticized AD by the FDA. Nevertheless, it has considerable prestige among clinicians for the treatment of severe depression, due in part to its being often prescribed to high-risk groups. Patients assigned to venlafaxine had 6.19 times more risk of being hospitalized for depression compared to patients assigned to fluoxetine, and 4.34 times more than those who received citalopram. Regarding drug history, $27.7 \%$ of the group of venlafaxine patients received two or more $\mathrm{AD}$ during the last year, while among fluoxetine and citalopram users, 5.5\% and $11 \%$ respectively, reported such use. Table 3 illustrates the relative risks for general characteristics and behaviors related to suicide for venlafaxine, fluoxetine and citalopram ${ }^{51}$.

\section{Low plasma levels of antidepressants and discontinuation}

Several toxicological studies have revealed that a low proportion of suicide victims had considerable plasmatic levels of $\mathrm{AD}$, indicating that a large number of suicides occurred in people that were depressed and receiving no treatment, failed to adhere to indications, or who had discontinued the medication ${ }^{52-55}$. Relatedly, Isacsson et al. conducted post-mortem studies of suicides, and did not find plasmatic levels of SSRI in children below fifteen years old, while in the group between fifteen and nineteen years of age, the presence of SSRI was minor compared to other types of AD. This suggests that the hypothesis of suicide being induced by SSRI was not supported by autopsy data ${ }^{56}$, while also concluding that the increase in AD usage in Sweden had been parallel to a significant decrease in suicide rates there.

Meanwhile, Leon et al. studied 66 suicides which occurred in New York City between 1993 and 1998, the first six years that paroxetine was available in the United States. Subjects were under eighteen years of age, and chromatographic methods did not find, plasma levels of paroxetine ${ }^{57}$. In other research conducted in New York City which looked at 44 suicides among subjects less than eighteen years old between 1999 and 2002, in only one case (2,8\%) was sertraline and bupropion detected during the autopsy, while in all others no presence of any other AD was found ${ }^{58}$. From a sample of 1,635 suicide victims, Marzuk et al. showed that $16.4 \%$ had a psychotropic prescription, thus reinforcing the above evidence. From the toxicological analysis only $17.9 \%$ of deaths by poisoning were found, finding $\mathrm{AD}$ in less than half of these victims ${ }^{59}$. So it is supported that the presence of $\mathrm{AD}$ in suicidal teenagers is low, contradicting any direct relationship between SSRI usage and child and adolescent suicide ${ }^{14}$. Regarding the discontinuance of $\mathrm{AD}$, Yerevanian et al. found that the risk of committing suicide increased five times after suspending $\mathrm{AD}$ therapy, claiming that its use would serve as an anti-suicidal protective factor ${ }^{60}$.

\section{Discussion}

"Suicidal tendencies" are central to the FDA's stance against AD prescription, which raises the question: Is suicide an $\mathrm{AD}$ side effect or attributable to one of the affective disorders? In lieu of attributing suicidogenic characteristics to $\mathrm{AD}$, we must bear in mind that the regulatory associations do not consider the essential factors 
Table 3. Risk for behaviors and general characteristics related to suicide according to antidepressant

\begin{tabular}{|c|c|c|c|c|c|}
\hline \multirow[t]{2}{*}{ Characteristics } & \multirow{2}{*}{$\begin{array}{c}\text { Venlafaxine } \\
\mathrm{N}=27,096 \\
\mathrm{~N}(\%)\end{array}$} & \multirow{2}{*}{$\begin{array}{c}\text { Fluoxetine } \\
\mathrm{N}=134,996\end{array}$} & \multirow{2}{*}{$\begin{array}{c}\text { Citalopram } \\
\mathrm{N}=52,035 \\
\mathrm{~N}(\%)\end{array}$} & \multicolumn{2}{|c|}{ Relative risk } \\
\hline & & & & $\begin{array}{l}\text { Venlafaxine versus } \\
\text { fluoxetine }\end{array}$ & $\begin{array}{c}\text { Venlafaxine versus } \\
\text { citalopram }\end{array}$ \\
\hline \multicolumn{6}{|l|}{ Previous diagnosis } \\
\hline Major depressive disorder & $20,574(75.9)$ & $57,918(42.9)$ & $27,883(53.6)$ & 4.10 & 2.8 \\
\hline Bipolar disorder & $423(1.6)$ & $452(0.3)$ & $328(0.6)$ & 4.83 & 2.51 \\
\hline Schizophrenia & $705(2.6)$ & $1,343(1)$ & $714(1.4)$ & 2.70 & 1.91 \\
\hline Anxiety disorder & $10,210(37.7)$ & $28,788(21.3)$ & $15,560(29.9)$ & 2.13 & 1.45 \\
\hline \multicolumn{6}{|l|}{ 1-year previous event } \\
\hline Suicidal behaviors & $260(1)$ & $474(0.4)$ & $207(0.4)$ & 2.75 & 2.43 \\
\hline Suicidal behaviors that required hospitalization & $99(0.4)$ & $177(0.1)$ & $67(0.1)$ & 2.79 & 2.84 \\
\hline Hospitalization due to depression & $670(2.5)$ & $551(0.4)$ & $302(0.6)$ & 6.19 & 4.34 \\
\hline Another AD prescribed previously & $19,651(72.5)$ & $37,318(27.6)$ & $20,563(39.5)$ & 6.91 & 4.04 \\
\hline \multicolumn{6}{|l|}{ Number of prescribed $A D$ in the last year } \\
\hline 0 & 7,445 (27.5) & $97,678(72.4)$ & $31,472(60.5)$ & 0.14 & 0.25 \\
\hline 1 & $12,132(44.8)$ & $29,836(22.1)$ & $14,831(28.5)$ & 2.86 & 2.03 \\
\hline 2 or more & $7,519(27.7)$ & $7,482(5.5)$ & $5,732(11)$ & 6.55 & 3.1 \\
\hline \multicolumn{6}{|l|}{ Current drug usage } \\
\hline Mood stabilizers & $1,010(3.7)$ & $1,536(1.1)$ & $977(1.9)$ & 3.36 & 2.02 \\
\hline Anxiolytic & $2,740(10.1)$ & $6,893(5.1)$ & $4,253(8.2)$ & 2.09 & 1.26 \\
\hline Antipsychotic & $2,653(9.8)$ & $3,393(2.5)$ & $2,230(4.3)$ & 4.21 & 2.42 \\
\hline
\end{tabular}

Modified from Mines et al. ${ }^{51}$.

that research has demonstrated, such as the severity of depressive symptoms, existence of initial suicide ideation, despair, impulsivity, previous suicide attempts, psychiatric disorder and suicide family records, comorbidities with other psychiatric disorders (e.g. alcohol or drug abuse), medical pathologies linked to pain, treatment adherence, pharmacokinetic parameters (e.g. increased metabolism with lower plasmatic concentrations than the therapeutic ones), and time elapsed since the onset of treatment ${ }^{61}$. Neither the psychosocial factors nor easy access to any suicidal methods are considered. It is questionable to not only attribute suicide to $\mathrm{AD}$ per se but to the presence and increase of suicidal behaviors, especially sinced these behaviors are inherent to mood disorders, estimating that between $60 \%$ to $70 \%$ of depressive people experience suicidal ideation and between $10 \%$ to $15 \%$ actually commit suicide ${ }^{62}$. At first glance, the fact that significant differences are observed in comparison with placebo may allow one to conclude that $\mathrm{AD}$ induce suicidality; nevertheless, those findings can be methodologically questioned, due to the fact that researchers would rarely administer any placebo or $\mathrm{AD}$ to groups of patients with similar depressive severity due to ethical constraints, rendering them hardly comparable. An inherent problem with the FDA's systematic review is the retroactive gathering of relevant information, and the lack of a clear definition pertaining to suicide-related events. In this sense, only the Treatment for Adolescents with Depression Study ${ }^{63}$ comprehensively evaluated the phenomenon from initial quantities of suicidal ideation and associated behaviors. Suicide varies individually, thus only randomized trials with large sample sizes would have enough statistical significance to demonstrate any difference in the suicide rates linked to $\mathrm{AD}$ versus placebo. Nevertheless, with suicide being a low-frequency event, it is difficult to perform a clinical trial large enough to obtain a causal hypothesis. This is a problem that could be solved through meta-analyses of existing randomized clinical trials. However, the period of time clinical trials are usually conducted may me insufficient to establish long-term treatment benefits. Additionally, suicidal behaviors usually constitute exclusion criteria due to their ethical limitations and practical difficulties ${ }^{46}$.

Multiple factors exist which can be linked to the suicidality phenomenon. Firstly, not every AD is effective on any specific patient, nor is the prescribed dosage always sufficient to control the intensity of the symptoms. Another factor is the pharmacological switch from depression to mania (particularly from dysphoric to irritable mania) in bipolar patients treated with $\mathrm{AD}$ in absence of mood stabilizers ${ }^{64}$, leading to self-aggressive behaviors. In terms of treatment temporality, there appears to be an inverted relationship between suicidal behaviors and $\mathrm{AD}$ exposure time, raising the question as to what methodology was used in the studies selected by the FDA looking at suicide risk during the first days of therapy compared to the risk in people who do not receive AD. Also, unlike adults with whom psychiatric assistance is often sporadic, in child and adolescent psychiatry the patient is commonly brought to treatment by their parents. As such, professional assistance may be sought once the responsible adult perceives that there may be a serious clinical disorder or it if a suicide attempt has already occurred ${ }^{65,66}$.

The FDA clinical trials do not reflect sustained treatment, since in daily clinical practice the physician may prematurely interrupt the $\mathrm{AD}$ therapy due to unwanted adverse effects, to adjust the dosage or make changes to drug combinations ${ }^{67}$. It is precisely this type of practicebased AD treatment that has been successfully applied over the past thirty years in high-risk suicide depressive patients, mainly on an in-patient basis, whose follow up and control may have otherwise been adversely affected due to diverse constraints ${ }^{11}$. Considering that depression is the disorder most-linked to suicide ${ }^{68-70}$, it is reasonable to propose that a close surveillance of the patient could be a protector factor against the phenomenon, specially considering other variables, such as lack of response for SSRI $(20 \% \text { to } 30 \%)^{71}$, patient non-compliance ( $15 \%$ to $20 \%)^{72}$ and patients misreport about compliance (even higher in adolescents, particularly if there is no direct supervision). It is for this reason that fluoxetine, with a longer half life than the other SSRI, would not leave a "therapeutic gap" if the drug intake is irregular, which helps explain why fluoxetine has been the least challenged AD by the FDA.

Klein argue that the central concern of the FDA is that $\mathrm{AD}$ are potentially lethal, while it is unsupported by research on any case of suicide, instead using the concept of "suicidality" as a substitute for "suicide" and thus overestating the risk. Furthermore, the FDA's findings appear to be based on inferences, since the evidence was obtained in a manner that is not methodologically reliable, nor fulfilling the requirements of the definitions of "suicidal tendencies" utilized by the standardized scales 22 . 


\section{What factors linked to antidepressants could increase suicidality?}

Although Khan et al. ${ }^{73}$ and Gunnell et al. ${ }^{74}$ concluded that there was not an impact on suicide secondary to the use of $\mathrm{AD}$, there was an increase of self-aggressive behaviors. Some proposed mechanisms to explain the relationship among $\mathrm{AD}$, ideas, and suicidal behaviors ${ }^{75,76}$, are psychomotor stimulation, depression paradoxical deterioration, akathisia, panic attack or anxiety onset, pharmacological switch to mania, induction to obsessive concern with suicide, and aggressive "borderline reactions" or paroxysmal disorders to electroencephalogram that might alter impulse control ${ }^{61,73-76}$. For example, AD with short half-lives may induce, initially, serotonin level fluctuations, which may lead to akathisia, therefore increasing suicidal risk associated with desperation and unrest ${ }^{77}$.

In relation to genetic influence, Menke et al. did a genome-wide association study to identify genetic markers linked to emergent suicidal ideation resulting from the $\mathrm{AD}$ treatment, finding a very low proportion of genetic factors related to this phenomenon. The results suggest that combinations of some genetic markers could be used to identify patients with this risk ${ }^{78}$. Additionally, an investigation into clinical and genetic predictors of the increase of suicidal ideation by patients undergoing therapy with $\mathrm{AD}$ assessed the effects of paroxetine, venlafaxine, and clomipramine. The increase of suicidality was linked to the severity of the affective disorder and the $\mathrm{AD}$ treatment when some defined genetic sequences were present, with the exception of paroxetine, which did not show a significant relationship with the aforementioned risk. Some genome sequences were described as stronger guidelines than others in suicidal ideation increase across the therapy, whereas others exhibited a differential association according to the AD type. The FKBP5 gene that codifies proteins linked to glucocorticoid receptor would be associated with the misregulation of the hypothalamic-pituitary-adrenal axis during $\mathrm{AD}$ treatment, and the physiopathological mechanism was proposed as responsible for the increase in suicidal ideation. Nevertheless, the authors support the AD prescription in patients displaying suicidal ideation, taking into account the potential benefits of therapy 79 . Pan et al. described a crucial element of suicidality, independent of $\mathrm{AD}$ prescription, when reporting a new variant of guanosine tryphosphate cyclohidrolase deficiency in young men with severe major affective disorder with multiple suicide attempts. This deficiency was linked to some biochemical mediators in the biosynthetic pathways of serotonin and dopamine in cerebral spinal fluid, demonstrating impairment in this metabolic pathway. Through the replacement of these mediators, suicidal ideation was lessened and there was significant improvement in the affective disorder ${ }^{80}$. Although these investigation trends are interesting, it would be overly-reductionist to only consider the biological-molecular aspects involved in the comprehension of suicide, regarding the inherent biopsychosocial nature of this topic.

\section{Epidemiological effects following FDA warning}

Approximately one month after the FDA warning was published, the prescription of $\mathrm{AD}$ in the United States had decreased by $10 \%$, and by June 2005 it had decreased an additional $10 \% 81$. Simultaneously, Hamilton et al. noted that after ten years of decrease in the annual suicide rates in North American children and teenagers, an increase of $18 \%$ was observed in people between one and nineteen years of age during 2003 and 2004, suggesting that this change may be the result of the FDA recommendation ${ }^{82}$. In a comparative analysis, Gibbons et al. found that the usage of SSRI in children and adolescents decreased by $20 \%$ in the Netherlands and the United States, proving a correlation with the increase of the $49 \%$ and $14 \%$ in suicide rates, respectively ${ }^{83}$. Nevertheless, Kurdyak et al. stated that the FDA warning was not associated with a significant change in $\mathrm{AD}$ prescription in Ontario (Canada) in patients under twenty years old. Meanwhile, the British warning about the prescription of paroxetine in this population contributed to a significant decline in its prescription by $54 \%$ ( $p=0.03$ ) immediately after the first warning by the United Kingdom Committee on Safety of Medicines. The authors argue that the drastic change in paroxetine usage in contrast with $\mathrm{AD}$ prescription was due to the British warning being more specific, since it only covered one $\mathrm{AD}$. On the other hand, physicians in Ontario could have prescribed a substitute for paroxetine, while the FDA warning fell on an AD series, thereby leaving professionals without adequate replacement treatment options ${ }^{84}$.

These studies demonstrate a radically diametric effect from the warning issued by the FDA. It is clear that a posterior amplification of the black box warning had an additional impact on practice. In parallel, the FDA recommendation which suggests closer therapeutic contact does not consider the current problems of the mental health system, including low coverage by insurance plans for mental disorders, strict limits on visits to hospitalized and ambulatory patients, restricted access to mental health providers, inter alia. Additionally, the current deficit in professionals (child and youth psychiatrists in particular) is not expected to be reversed in the short term, which may be seen as a reason why this tight control becomes difficult ${ }^{85}$.

\section{Conclusions}

Aside from being contradictory to present evidence, assigning a suicidogenic role to $\mathrm{AD}$ implies debugging every biological, social and psychological factor that impacts the act of suicide, which itself is a multifactorial phenomenon, and thus not attributable to a single cause. Indeed, many studies that underpin the FDA's stance on AD and suicide risk are still unknown to the scientific world, while others lack a rigorous methodology, or indicate results that do not reach statistical significance. Although the therapeutic effects of SSRI and venlafaxine in young patients may be limited, reasonable evidence does exist which supports its use in the treatment of depression. Based on this, the FDA warning itself might paradoxically be contributing to an increase in suicide rates.

\section{Financial disclosure}

Authors also declare that no financial compensation nor support has been received from any individual or corporate pharmaceutical companies in the last 5 years. There are no personal financial holdings that may constitute a potential conflict of interest.

\section{Conflict of interest}

The authors declare that there is no conflict of interests regarding the publication of this paper.

\section{References}

1. Birmaher B, Ryan ND, Williamson DE, Brent DA, Kaufman J. Childhood and adolescent depression: a review of the past 10 years, part 1 . J Am Acad Child Adolesc Psychiatry. 1996;35:1427-39.

2. Henriksson MM, Aro HM, Martunnen MJ. Mental disorders and comorbidity in suicide. Am J Psychiatry. 1993;150:935-40.

3. Balazs J, Lecrubier Y, Csiszer N, Kosztak J, Bitter L. Prevalence and comorbidity of affective disorders in people making suicide attempts in Hungary: importance of the first depressive episodes and of bipolar II diagnoses. J Affect Disord. 2003;76:113-9.

4. Shafii M, Lenarsky J, Derrick AM, Beckner C, Whittinghill JR. Comorbidity of mental disorders in the post-mortem diagnosis of completed suicide in children and adolescents. J Affect Disord. 1988;15:227-33.

5. Rao U, Weissman MM, Martin JA, Hammond RW. Childhood depression and risk of suicide: a preliminary report of a longitudinal study. J Am Acad Child Adolesc Psychiatry. 1993;32:21-7.

6. American Psychiatric Association. Diagnostic and statistical manual of mental disorders. Fifth Edition. Washington, DC: American Psychiatric Association, 2013. 
7. Kessing L. Severity of depressive episodes according to ICD-10: prediction of risk of relapse and suicide. Br J Psychiatry. 2004;184:153-6.

8. van Heering C. Suicide in adolescents. Int Clin Psychopharmacol. 2001;16:1-6.

9. Lapid MI, Rummans TA. Evaluation and management of geriatric depression in primary care. Mayo Clin Proc. 2003;78:1423-9.

10. Remick RA. Diagnosis and management of depression in primary care: a clinical update and review. CMAJ. 2002;167:1253-60.

11. Healy D, Aldred G. Antidepressant drug use \& the risk of suicide. Int Rev Psychiatry. 2005;17:163-72.

12. Teicher MH, Glod C, Cole JO. Emergence of intense suicidal preoccupation during fluoxetine treatment. Am J Psychiatry. 1990;147:207-10.

13. Busch SH, Barry CL. Pediatric antidepressant use after the black-box warning. Health Aff. 2009;28:724-33.

14. Kutcher S, Gardner DM. Use of selective serotonin reuptake inhibitors and youth suicide: making sense from a confusing story. Curr Opin Psychiatry. 2008;21:65-9.

15. Henry A, Kisicki MD, Varley C. Efficacy and safety of antidepressant drug treatment in children and adolescents. Mol Psychiatry. 2012;17:1186-93.

16. Silva $\mathrm{H}$, Martínez JC. ¿Es efectivo que los antidepresivos aumentan el riesgo de suicidio? Rev Med Chile. 2007;135:1195-201.

17. Möller HJ. SSRIs: are the accusations justified? World J Biol Psychiatry. 2004;5:174-5.

18. Goode E. British warning on antidepressant use for youth. The New York Times [Internet]. 2003 [cited 20 July 2013]. Available from: <http://www. nytimes.com/2003/12/11/world/british-warning-on-antidepressant-usefor-youth.html>.

19. Brent DA, Birmaher B. British warnings on SSRIs questioned. J Am Acad Child Adolesc Psychiatry. 2004;43:4.

20. Fda.gov. US Food and Drug Administration Home Page [Internet]. 2015 [cited 3 February 2005]. Available from: <http://www.fda.gov>.

21. Vedantam S. Fewer kids prescribed drugs for depression-sharp decrease seen after reports of risks. The Washington Post [Internet]. 2005 [cited 10 August 2013]; A08. Available from: <http://www.washingtonpost.com/ wp-dyn/articles/A55371-2005Feb1.html $>$.

22. Klein DF. The flawed basis for FDA post-marketing safety decisions: the example of antidepressants and children. Neuropsychopharmacology. 2006;31:689-99.

23. Cheung AH, Emslie GJ, Mayes TL. Review of the efficacy and safety of antidepressants in youth depression. J Child Psychol Psychiatry. 2005;46:735-54.

24. Fda.gov. 2005 Warning Letters [Internet]. 2005 [cited 1 November 2013]. Available from: <http://www.fda.gov/ICECI/EnforcementActions/ WarningLetters/2005/default.htm $>$.

25. Hammad TA, Laughren T, Racoosin J. Suicidality in pediatric patients treated with antidepressant drugs. Arch Gen Psychiatry. 2006;63:332-9.

26. Hetrick SE, McKenzie JE, Cox GR, Simmons MB, Merry SN. Newer generation antidepressants for depressive disorders in children and adolescents. Cochrane Database Syst Rev. 2012;11:CD004851.

27. Bridge JA, Iyengar S, Salary CB. Clinical response and risk for reported suicidal ideation and suicide attempts in pediatric antidepressant treatment: a meta-analysis of randomized controlled trials. JAMA. 2007;297:1683-96.

28. Dubicka B, Hadley S, Roberts C. Suicidal behavior in youths with depression treated with new-generation antidepressants: meta-analysis. Br J Psychiatry. 2006;189:393-8.

29. Aacap.org. Facts for families [Internet]. 2012 [cited 8 January 2014]. Available from: <http://www.aacap.org/AACAP/Families_and_Youth/ Facts_for_Families/Facts_for_Families_Keyword.aspx $>$.

30. Regan J, DeWire M, Whitby B, Bess T, Wright A. The "black box" controversy. Tenn Med. 2005;98:41-2.

31. AACAP Recommends Monitoring, research and access in antidepressant use - workforce support critical. Child Adolesc Psychopharmacol News. 2004;9:7-8.

32. Cooper WO, Callahan ST, Shintani A, Fuchs DC, Shelton RC, Dudley JA, et al. Antidepressants and suicide attempts in children. Pediatrics. 2014;133:204-10.

33. Plener PL, Fegert JM, Kölch MG. The psychopharmacological treatment of depressive disorders in childhood and adolescence - developments and standards since the "black box" warning. Z Kinder Jugendpsychiatr Psychother. 2012;40:365-71.
34. O'Leary D, Paykel E, Todd C, Vardulaki K. Suicide in primary affective disorders revisited: a systematic review by treatment era. J Clin Psychiatry. 2001;62:804-11.

35. Agdebite-Adeniyi C, Gron B, Rowles BM, Demeter CA, Findling RL. An update on antidepressant use and suicidality in pediatric depression. Expert Opin Pharmacother. 2012;13:2119-30.

36. Kuba T, Yakushi T, Fukuhara H, Nakamoto Y, Singeo ST, Tanaka O, et al. Suicide-related events among child and adolescent patients during shortterm antidepressant therapy. Psychiatry Clin Neurosci. 2011;65:239-45.

37. McKeown RE, Cuffe SP, Schulz RM. US suicide rates by age group, 1970-2002: an examination of recent trends. Am J Public Health. 2006;96:1744-51.

38. Cdc.gov. National Center for Health Statistics. Leading Causes of Death 1900-1998. 2013 [cited 20 November 2013] Available from: <http://www. cdc.gov/nchs/data/dvs/lead1900_98.pdf>.

39. Anderson N. Deaths: leading causes for 1999. Natl Vital Stat Rep. 2001;49:1-88.

40. Minino AM, Arias E, Kochanek KD, Murphy SL, Smith BL. Deaths: final data for 2000. Natl Vital Stat Rep. 2002;50:1-120.

41. Arias E, Anderson RN, Kung HC, Murphy SL, Kochanek KD. Deaths: final data for 2001. Natl Vital Stat Rep. 2003;52:1-116.

42. Grunebaum MF, Ellis SP, Li S, Oquendo MA, Mann JJ. Antidepressants and suicide risk in the United States, 1985-1999. J Clin Psychiatry. 2004;65:1456-62.

43. Olfson M, Shaffer D, Marcus SC, Greenberg T. Relationship between antidepressant medication treatment and suicide in adolescents. Arch Gen Psychiatry. 2003;60:978-82.

44. Gibbons RD, Hur K, Bhaumik DK, Mann JJ. The relationship between antidepressant prescription rates and rate of early adolescent suicide. Am J Psychiatry. 2006;163:1898-904.

45. Dave J, Marcotte E. Antidepressants, suicide, and drug regulation. J Policy Anal Manage. 2005;24:249-72.

46. Bramness JG, Walby FA, Tverdal A. The sales of antidepressants and suicide rates in Norway and its counties 1980-2004. J Affect Disord. 2007;102:1-9.

47. Nakagawa A, Grunebaum MF, Ellis SP, Oquendo MA, Kashima H, Gibbons RD, et al. Association of suicide and antidepressant prescription rates in Japan, 1999-2003. J Clin Psychiatry. 2007;68:908-16.

48. Simon GE, Savarino J, Operskalski B, Wang PS. Suicide risk during antidepressant treatment. Am J Psychiatry. 2006;163:41-7.

49. Simon GE, Savarino J. Suicide attempts among patients starting depression treatment with medications or psychotherapy. Am J Psychiatry. 2007;164:1029-34.

50. Jick H, Kaye JA, Jick SS. Antidepressants and the risk of suicidal behaviors. JAMA. 2004;292:338-43.

51. Mines D, Hill D, Yu H, Novelli L. Prevalence of risk factors for suicide in patients prescribed venlafaxine, fluoxetine, and citalopram. Pharmacoepidemiol Drug Saf. 2005; 14:367-72.

52. Isacsson G, Bergman U, Rich CL. Antidepressants, depression and suicide: an analysis of the San Diego study. J Affect Disord. 1994;3:277-86.

53. Isacsson G, Holmgren P, Druid H, Bergman U. The utilization of antidepressants - a key issue in the prevention of suicide: an analysis of 5,281 suicides in Sweden during the period 1992-1994. Acta Psychiatr Scand. 1997;96:94-100.

54. Henriksson S, Boethius G, Isacsson G. Suicides are seldom prescribed antidepressants: findings from a prospective prescription database in Jamtland county, Sweden, 1985-95. Acta Psychiatr Scand. 2001;103:301-6.

55. Marzuk PM, Tardiff K, Leon AC, Hirsch CS, Stajic M, Hartwell N, et al. Use of prescription psychotropic drugs among suicide victims in New York City. Am J Psychiatry. 1995;152:1520-2.

56. Isacsson G, Holmgren P, Ahlner J. Selective serotonin reuptake inhibitor antidepressants and the risk of suicide: a controlled forensic database study of 14,857 suicides. Acta Psychiatr Scand. 2005;111:286-90.

57. Leon AC, Marzuk PM, Tardiff K, Teres JJ. Paroxetine, other antidepressants and youth suicide in New Cork City: 1993 through 1998. J Clin Psychiatry. 2004;65:915-8.

58. Leon AC, Marzuk PM, Tardiff K, Bucciarelli A, Markham Piper T, Galea S. Antidepressants and youth suicide in New York City, 1999-2002. J Am Acad Child Adolesc Psychiatry. 2006;45:1054-8.

59. Marzuk PM, Tardiff PM, Leon AC, Hirsch CS, Stajic M, Hartwell N, et al. Use of prescription psychotropic drugs among suicide victims in New York City. Am J Psychiatry. 1995;152:1520-2. 
60. Yerevanian BI, Koek RJ, Feusner JD, Hwang S, Mintz J. Antidepressants and suicidal behavior in unipolar depression. Acta Psychiatr Scand. 2004;110:452-8.

61. Rihmer Z, Akiskal H. Do antidepressants $t(h)$ reat(en) depressives? Toward a clinically judicious formulation of the antidepressant-suicidality FDA advisory in light of declining national suicide statistics from many countries. J Affect Disord. 2006;94:3-13.

62. Möller HJ. Suicide, suicidality and suicide prevention in affective disorders. Acta Psychiatr Scand. 2003;(418):73-80.

63. March J, Silva S, Petrycki S. Fluoxetine, cognitive-behavioral therapy, and their combination for adolescents with depression: Treatment for Adolescents With Depression Study (TADS) randomized controlled trial. JAMA. 2004;292:807-20.

64. Shia L, Thiebaudb P, McCombsb JS. The impact of unrecognized bipolar disorders for patients treated for depression with antidepressants in the fee-for-services California Medicaid (Medi-Cal) program. J Affec Disord. 2004;82:373-83.

65. Nardi B, Francesconi G, Catena-Dell'osso M, Bellantuono. Adolescent depression: clinical features and therapeutic strategies. Eur Rev Med Pharmacol Sci. 2013;17:1546-51.

66. Emslie G, Mayes T. Depression in Children and Adolescents: Guide to Diagnosis and Treatment. CNS Drugs. 1999;11:181-9.

67. Eurekalert!. Antidepressants in suicide prevention [Internet]. 2008 [cited 8 January 2014]. Available from: <http://www.eurekalert.org/ pub_releases/2008-08/econ-ais082708.php>.

68. Apter A, Bleich A, King RA, Kron S, Fluch A, Jotler M, Cohen DJ. Death without warning?. Arch Gen Psychiatry. 1993;30:138-42.

69. Marttunen MJ, Aro HM, Henriksson MM, Lönnqvist JK. Mental disorder in adolescent suicide. Arch Gen Psychiatry. 1991;48:834-9.

70. Cheng AT. Mental illness and suicide. Arch Gen Psychiatry. 1995;52:594-603.

71. Zonda T. Depression and suicidal behavior. Crisis. 2005;26:34-5.

72. Schrader E, Meier B, Brattström A. Hypericum treatment of mild-moderate depression in a placebo-controlled study. Human Psychopharmacol Clin Exp. 1998;3:163-9.

73. Khan A, Khan S, Kolts R, Brown WA. Suicide rates in clinical trials of SSRIs, other antidepressants, and placebo: analysis of FDA reports. Am J Psychiatry. 2003;160:790-2.

74. Gunnell D, Saperia J, Ashley D. Selective serotonin reuptake inhibitors (SSRIs) and suicide in adults: meta-analysis of drug company data from placebo controlled, randomized controlled trials submitted to the MHRA's safety review. BMJ. 2005;330:385-9.

75. Teicher MH, Glod CA, Cole JO. Antidepressant drugs and the emergence of suicidal tendencies. Drug Safety. 1993;8:186-212.

76. Fda.gov. Background Comments for February 2, 2004. Meeting of Psychopharmacological Drugs Advisory Committee (PDAC) and Pediatric Subcommittee of the Anti-Infective Drugs Advisory Committee (Peds-AC) [Internet]. 2004 [cited 25 November 2013]. Available from: $<$ www.fda.gov/OHRMS/DOCKETS/ac/04/briefing/4006B1_03_ Background\%20Memo\%2001-05-04.pdf >.

77. Delavenne H, García FD, Thibaut F. Do antidepressant treatments influence self-harm and agressive behaviors?. Presse Med. 2013;42:968-76.

78. Menke A, Domschke K, Czamara D, Klengel T, Hennings J, Lucae S, et al. Genome-wide association study of antidepressant treatment-emergent suicidal ideation. Neuropsychopharmacology. 2012;37:797-807.

79. Perroud N, Bondolfi G, Uher R, Gex-Fabry M, Aubry JM, Bertschy G, et al Clinical and genetic correlates of suicidal ideation during antidepressant treatment in a depressed outpatient sample. Pharmacogenomics. 2011;12:365-77.

80. Pan L, McKain BW, Madan-Khetarpal S, McGuire M, Diler RS, Perel JM, et al. GTP-cyclohydrolase deficiency responsive to sapropterin and 5-HTP supplementation: relief of treatment-refractory depression and suicidal behaviour. BMJ Case Rep. 2011;2011. pii: bcr0320113927.

81. Rosack J. New data show declines in antidepressant prescribing. Psychiatric News [Internet]. 2005 [cited 15 September 2013]; 1. Available from: $<$ http://pn.psychiatryonline.org/cgi/content/full/40/17/1-a $>$.

82. Hamilton BE, Minino AM, Martin JA, Kochanek KD, Strobino DM, Guyer B. Annual summary of vital statistics 2005. Pediatrics. 2007;119:345-60.

83. Gibbons RD, Brown CH, Hur K. Early evidence on the effects of regulators' suicidality warnings on SSRI prescriptions and suicide in children and adolescents. Am J Psychiatry. 2007;164:1356-63.

84. Kurdyak PA, Juurlink DN, Mamdani MM. The effect of antidepressant warnings on prescribing trends in Ontario, Canada. Am J Public Health. 2007;97:750-4.

85. Hetrick SE, Thompson A, Yuen K, Finch S, Parker AG. Is there a gap between recommended and 'real world' practice in the management of depression in young people? A medical file audit of practice. BMC Health Serv Res. 2012;12:178. 